\title{
Dedifferentiated Chondrosarcoma
}

National Cancer Institute

\section{Source}

National Cancer Institute. Dedifferentiated Chondrosarcoma. NCI Thesaurus. Code C6476.

An aggressive morphologic variant of chondrosarcoma. It is composed of a low grade chondrosarcoma and a high grade non-cartilagenous sarcomatous component. Due to the agg ressive nature of the disease, its prognosis is poor. 